Available online on 15.05.2020 at http://jddtonline.info
Open Access to Pharmaceutical and Medical Research
(c) 2011-18, publisher and licensee JDDT, This is an Open Access article which permits
unrestricted non-commercial use, provided the original work is properly cited

Open $\odot$ Access

Research Article

\title{
Formulation and Evaluation of Protein Bound Paclitaxel Nanoparticles for Injectable Suspension
}

\author{
Surendra Kumar Jain ${ }^{1 *}$, Suchi Thakur ${ }^{1}$, Ruchi Jain ${ }^{1}$ and Nilesh Jain ${ }^{2}$ \\ 1 Sagar Institute of Research \& Technology -Pharmacy, Ayodhya Bypass Road, Bhopal -462041 \\ ${ }^{2}$ Sagar Institute of Research Technology \& Science-Pharmacy, Ayodhya Bypass Road, Bhopal - 462041
}

\begin{abstract}
Aims: The aim of present study is to develop Paclitaxel nanoparticles for injectable suspension, an anti-neoplastic drug formulation.

Study design: Mention the design of the study here.
\end{abstract}

Place and Duration of Study: Sagar Institute of Research \& Technology- Pharmacy, Ayodhya Bypass Road, Bhopal, between June 2017 and June2018.

Methodology: The Human serum albumin (HSA) is the most abundant plasma protein in the human blood with a half-life of 19 days. It can reversibly bind hydrophobic drug substances, transport them in the body and release drugs at cell surface. The formulation is prepared by homogenization at high-pressure of paclitaxel in the presence of human serum albumin into a nanoparticle colloidal suspension. Paclitaxel nano particles have been stabilized by human albumin and maintain the average size of $100 \mathrm{~nm}$

Results: The particle size of the reconstituted solution is checked using the laser diffraction Technique the particle is White to yellow lyophilized after reconstitution the particle become homogeneous milky suspension without visible particulates. Reconstitution time NMT 25 minutes $20.45 \mathrm{sec}$. The assay was performed by HPLC and found to be $90.0 \%$ to $110.0 \%$ of label. The retention time of Paclitaxel peak obtained in sample corresponds to the respective standards obtained from standards the pH NLT 6.00 to NMT 8.00 Particle size NLT 100 nm - NMT 200 nm. Sterility test was comply as per USP $<71>$

Conclusion: The nano-delivery systems could have the potential to be free of Cremophor EL and ethanol, enhance Paclitaxel solubility, improve Paclitaxel pharmacokinetic profiles in vivo, decrease its side effects, passively or actively target to tumor sites due to the EPR (Enhanced Permeability and Retention) effect and the use of targeting ligands, respectively, nanotechnology is a very active research area in both academic and industrial settings.

Keywords: paclitaxel, Anti-cancer, nanotechnology, Injectable, Suspension

Article Info: Received 07 March 2020; Review Completed 10 April 2020; Accepted 16 April 2020; Available online 15 May 2020

Cite this article as:

Jain SK, Thakur S, Jain R, Jain N, Formulation and Evaluation of Protein Bound Paclitaxel Nanoparticles for Injectable Suspension, Journal of Drug Delivery and Therapeutics. 2020; 10(3):51-57 http://dx.doi.org/10.22270/jddt.v10i3.3979

*Address for Correspondence:

Dr. Nilesh Jain, Sagar Institute of Research Technology \& Science-Pharmacy, Near ISRO, Ayodhya Bypass Road, Bhopal -

462041

\section{INTRODUCTION}

Paclitaxel (PX), isolated from the bark of Pacific Yew (Taxus brevifolia), which was first discovered by Mrs. Monroe E. Wall and Mansukh C. Wani, is a white crystalline powder with the melting point of $\sim 210^{\circ} \mathrm{C}$. It is one of the most effective chemotherapeutic drugs and is mainly used to treat lung, ovarian, and breast cancer, etc. The mechanism of action of PX is to promote and stabilize microtubules and inhibit late G2 or M phases of cell cycle, thereby causing the cell death. The major limitation of PX is its low water solubility $(\sim 0.4 \mu \mathrm{g} / \mathrm{mL})$; thus, it is formulated in organic solvents of polyoxyethylated castor oil (Cremophor EL) and dehydrated ethanol $(50 / 50, \mathrm{v} / \mathrm{v})$ under the trademark "Taxol". However, Cremophor EL is known to cause serious side effects, such as hypersensitivity reactions. As a result, prolonged infusion time and pretreatments are required. Moreover, the presence of Cremophor EL alters the pharmacokinetic profile of PX in vivo which was described as unpredictable non-linear plasma pharmacokinetics when PX was formulated in Cremophor EL. In addition, PX is a substrate of P-glycoprotein (P-gp), which actively pumps PX out of the cells and induces drug resistance. To overcome this problem, several P-gp inhibitors, such as verapamil and 
PSC 833, were co-administered with Taxol but the results were disappointing due to their toxicity and/or alteration of PX pharmacokinetics and biodistribution. Nano-delivery systems are promising vehicles in drug delivery because they improve solubility of hydrophobic drugs, such as PX, and generally have low toxicity as well.

Nanoparticle delivery systems have attracted increasing attention in recent years, especially for cancer therapies. As an effective chemotherapeutic agent, PX has been formulated in various nano-delivery systems which have several advantages over the standard-of-care therapy. First, the aqueous solubility of PX can be greatly enhanced when it is conjugated with water-soluble polymers, or encapsulated into lipid-based NPs. Second, they are small in size (several to several hundred nanometers in diameter), which enables the preferential delivery of PX into the tumor site due to the enhanced permeability and retention (EPR) effect. Third, they can escape the recognition of reticuloendothelial system (RES) in healthy tissues and therefore reduce the side effects of the drug. As a consequence, higher maximum tolerated doses (MTD) of NPs are realized. It should be noted that, in general, the addition of polyethylene glycol (PEG) on the surface of NPs is required to avoid RES clearance. Fourth, the pharmacokinetic profiles of the drug from NPs is improved, for example, increasing the half-life and tumor accumulation of PX. Last, but not the least, the surface of PX NP systems can be functionalized with active ligands for targeting purpose, which in-turn will further increase the tumor uptake and decrease the side effects of the drug 1-6.

Paclitaxel is one of the most effective chemotherapeutic drugs ever developed and is active against a broad range of cancers, such as lung, ovarian, and breast cancers. Due to its low water solubility, paclitaxel is formulated in a mixture of Cremophor EL and dehydrated ethanol (50:50, v/v) a combination known as Taxol. However, Taxol has some severe side effects related to Cremophor EL and ethanol. Therefore, there is an urgent need for the development of alternative Taxol formulations. The encapsulation of paclitaxel in biodegradable and nontoxic nano-delivery systems can protect the drug from degradation during circulation and inturn protect the body from toxic side effects of the drug thereby lowering its toxicity, increasing its circulation half-life, exhibiting improved pharmacokinetic profiles, and demonstrating better patient compliance. Also, nanoparticle-based delivery systems can take advantage of the enhanced permeability and retention (EPR) effect for passive tumor targeting, therefore, they are promising carriers to improve the therapeutic index and decrease the side effects of paclitaxel.

Albumin is a versatile natural protein carrier for targeted drug delivery. Human serum albumin (HSA) is the most abundant plasma protein in the human blood with a half-life of 19 days. Albumin has a number of characteristics that make it an attractive drug vehicle in oncology. It is a natural carrier of endogenous hydrophobic molecules (such as vitamins, hormones, and other water-insoluble plasma substances), that are bound in a reversible non-covalent manner ${ }^{7-9}$ Moreover albumin seems to help endothelial transcytosis of protein-bound and unbound plasma constituents principally through binding to a cell-surface, 60-kDa glycoprotein (gp60) receptor (albondin). gp60 binds to caveolin-1 (an intracellular protein) with subsequent formation of transcytotic vesicles (caveolae).10-13 Also, osteonectin (known as secreted protein acid rich in cysteine [SPARC]) has been shown to bind albumin because of a sequence homology with gp60. SPARC, as caveolin-1, is often present in some neoplasms (breast, lung, and prostate cancer), which could explain why albumin is known to accumulate in some tumors and thus facilitates intratumor accumulation of albumin-bound drugs. ${ }^{7}$ Albumin-bound (nab-)paclitaxel ABI-007 (Abraxane®; Abraxis BioScience and AstraZeneca) is another example of an EPR-based nanovector application for breast cancer. It represents one of the strategies adopted to overcome the solvent-related problems of paclitaxel and it has been recently approved by the US Food and Drug Administration for pretreated metastatic breast cancer patients.ABI-007 is a novel, albumin-bound, 130-nm particle formulation of paclitaxel, free from any kind of solvent.14-15 It is used as a colloidal suspension derived from the lyophilized formulation of paclitaxel and human serum albumin diluted in saline solution $(0.9 \% \mathrm{NaCl})$. In detail human serum albumin stabilizes the drug particle at an average size of $130 \mathrm{~nm}$ which prevents any risk of capillary obstruction and does not necessitate any particular infusion systems or steroid/antihistamine premedication before the infusion. ${ }^{16}$ Preclinical studies, conducted in athymic mice with human breast cancer, demonstrated that ABI-007 has a higher penetration into tumor cells with an increased anti-tumor activity, compared with an equal dose of standard paclitaxel.16-17 A phase I clinical study by Ibrahim, conducted on 19 patients with solid tumors and breast cancer, showed a maximum tolerated dose of $\mathrm{ABI}-007$ about $70 \%$ higher than that of CrEL paclitaxel formulation $(300 \mathrm{mg} / \mathrm{m} 2$ for an every 3 weeks regimen). Dose-limiting toxicities were sensory neuropathy, stomatitis, and ocular toxicity (superficial keratopathy and blurred vision at a dose of 375 $\mathrm{mg} / \mathrm{m}^{2}$ ). No patients experienced hypersensitivity reactions. ABI-007 was administered intravenously with no premedication, in shorter infusion periods ( 30 minutes vs 3 hours for polyoxyethylated castor oil-based paclitaxel) and with a standard infusion device. Moreover, pharmacokinetic parameters showed a linear trend. 18 A phase II trial confirmed that ABI-007 has important antitumor activity in patients with metastatic breast cancer. The overall response rate (at a dose of $300 \mathrm{mg} / \mathrm{m} 2$ every 3 weeks) was $48 \%$ for all patients and $64 \%$ for patients in first line therapy. Time to tumor progression was 26.6 weeks for all patients and 48.1 weeks for patients with confirmed tumor responses; median overall survival was 63.6 weeks. No severe ocular events were noted, and other common taxane-associated toxicities were less frequent and less severe (eg, myelosuppression, peripheral neuropathy, nausea, vomiting, fatigue, arthralgia, myalgia, alopecia). ${ }^{19}$

In a large international randomized phase III study, equitoxic doses of ABI-007 (260 mg/m $\left.\mathrm{m}^{2}\right)$ and polyoxyethylated castor oil-based paclitaxel $(175 \mathrm{mg} / \mathrm{m} 2)$ were compared in 454 patients with metastitic breast cancer. ABI-007 was superior to standard paclitaxel for both overall response rate (33\% vs $19 \%$, respectively; $p=0.001$ ) and time to tumor progression $(\mathrm{p}=0.006)$ in all subgroups of patients, but mostly for those receiving the drug as fi rstline therapy ( $42 \%$ vs $27 \%$, respectively; $p=0.029$ ). Also in this trial the incidence of toxicities was significantly lower in the ABI-007 group than the polyoxyethylated castor oilbased paclitaxel group; in particular, grade 4 neutropenia was lower $(10 \%$ vs $21 \%$, respectively; $p=0.001)$ despite the approximately $50 \%$ higher dose. On the other hand, grade 3 sensory neuropathy was more frequent in the ABI-007 group $(10 \%$ vs $2 \%$, respectively; $p=0.001)$, but it was easily managed.20

The authors explained the increased antitumor activity of ABI-007 by the higher intratumor paclitaxel concentrations (as reported in preclinical studies) and higher dose administered.21 Neymann et al demonstrated also that weekly dosing of $\mathrm{ABI}-007$ is safe and produces minimum 
toxic adverse effect with objective antitumor responses in patients previously exposed to paclitaxel. ${ }^{21}$

\section{EXPERIMENTAL}

\section{Material:}

The active pharmaceutical ingredient, Paclitaxel is compendial in USP. The API used for this project was manufactured by Teva Czech Industries s.r.o, Czech Republic. Chloroform, Ethanol obtained from Merck India Ltd. Human Albumin USP were procured from seracare. All chemicals are analytical grade (AR).

\section{Method:}

\section{Nanoparticles Preparation:}

In this study, various parameters crucial in the preparation of Pacitaxal-HSA-NPs of sizes 100-200 nm were optimized using a high pressure homogenizer. The working of the high pressure homogenizer is based on the principal that applying a very high pressure $(5,000-60,000 \mathrm{psi})$ to the emulsion passed through a homogenization valve breaks the emulsion into nano-sized emulsion droplets evaporating the organic solvent from the emulsion leads to the formation of nanoparticles.

Paclitaxel was dissolved in part Chloroform - Ethanol (9:1) mixture in glass Duran bottle. Collect specified quantity of water for injection and cool to $10 \pm 2{ }^{\circ} \mathrm{C}$ in SS $316 \mathrm{~L}$ manufacturing tank. To the above water for injection, add batch quantity of $25 \%$ Human albumin solution under continuous stirring (slow stirring to avoid foaming) for 10 minutes. Add the drug solution from step 1 to Albumin solution of Step 3 under high shear mixing to form a white homogenous emulsion (Primary emulsion). The primary emulsion is subjected to high pressure homogenization. The homogenized bulk is subjected to immediate solvent evaporation by using thin film evaporator.

The remaining bulk is stored under $2-8{ }^{\circ} \mathrm{C}$ till further processing. Make up the volume to batch size and continue the stirring at $200-400$ RPM for 15 minutes. Warm the bulk at $35^{\circ} \mathrm{C}-40^{\circ} \mathrm{C}$ and proceed for filtration using $1.00 \mu$ glass fiber pre-filter immediately proceed for 1st filtration using $(0.45+0.2 \mu)$ Cellulose acetate filter. Maintain the bulk temperature between $35^{\circ} \mathrm{C}-40^{\circ} \mathrm{C}$. Immediately proceeds for $2^{\text {nd }}$ filtration using $(0.45+0.2 \mu)$ Cellulose acetate filter. The bulk is further filled in USP type I moulded glass vials and subjected to Lyophilisation.

\section{Selection of Homogenization Technique:}

Trials were conducted with high shear homogenizer and high speed mixer to evaluate its impact on particle size distribution and $\mathrm{Z}$ average of the final bulk. The stirrer/ mixer evaluated were top mounted High shear homogenizer (Make: Miccra) against bottom mounted high shear mixer (Make: Merck Millipore). Based on the equipment capability, the high shear homogenizer was operated at 17000 RPM for 5 minutes and the bottom mounted high shear mixer was operated at 2850 RPM for 30 minutes. Primary emulsion of both the batches was analysed for particle size.

\section{Selection of Processing Temperature for Primary Emulsion:}

The drug product contains Albumin, which being a protein is highly susceptible to high temperature and gets denatured. The drug substance is sensitive to thermal degradation and the exposure to higher temperature during processing may lead to degradation of the drug product. Thus maintaining of temperature during processing is critical. As per the proposed process, primary emulsion is subjected to high pressure homogenization. High pressure homogenization imparts shear and cavitation leading to appreciable increase in bulk temperature. The approximate heat rise after homogenization is 2 degree/100 bars. Thus the bulk temperature is expected to increase by about 25 degree after homogenization at about 1300 bar. Hence it was recommended to bring the primary emulsion to a temperature of $10 \pm 2^{\circ} \mathrm{C}$ before subjecting it to high pressure homogenization. This would restrict the bulk from achieving higher temperature.

\section{Organic Solvent Removal:}

The equipment proposed to be used for organic solvent removal from the product was thin film evaporator (namely: HYVAP). Various trials were conducted during the machine installation phase to understand the machine capability and the critical and optimum parameters of the process. The initial trials taken for identification of critical parameters with either water or model solvents (i.e. Tween 80 or mixture with water as a feed).

Drug product or placebo for Paclitaxel protein-bound particle for injectable suspension (albumin bound) $100 \mathrm{mg} /$ vial was not used in these trials; however the observations of these trials formed the basis for setting the critical parameters for the drug product Table 1.

Table 1: Critical evaporation parameter

\begin{tabular}{|c|c|c|}
\hline \multicolumn{3}{|c|}{ Trial Matrix } \\
\hline Feed rate range evaluated $(\mathrm{kg} / \mathrm{hr})$ & Jacket temp range evaluated $\left({ }^{\circ} \mathrm{C}\right)$ & Pressure (Vacuum) range evaluated (mbar) \\
\hline $80-100$ & $30-50$ & $20-50$ \\
\hline
\end{tabular}

\section{Selection of Filtration Method:}

Terminal sterilization is the preferred method of choice to render a sterile product. However, the choice of method of sterilization depends on the sensitivity of the raw materials used in the formulation and also the finished product dosage form. The forced degradation data of Paclitaxel revealed that it is sensitive to heat. Also, Human albumin is not stable at higher temperature. Furthermore, the finished product is a lyophilized product. Hence terminal sterilization is not a feasible option. Thus, aseptic filtration and aseptic processing was chosen as method of sterilization of proposed product.

For filter compatibility Study PVDF, PES (supplied by Millipore, Sartorious) and Cellulose acetate (supplied by Sartorius) were evaluated. Materials were soaked in $80 \mathrm{~mL}$ drug product bulk individually for 16 hours at room temperature. Based on the inventory availability at unit, PVDF filter manufactured by Millipore, PES and Cellulose acetate filter manufactured by Sartorius were evaluated. The filter was removed from the bulk after static soaking and the bulk was analysed for Assay and degradation products. 


\section{Evaluation of Bulk Temperature for Filtration:}

The bulk product is proposed to be sterilized by filtration through sterilizing grade filters. Hence trials were performed to evaluate impact of bulk temperature on throughput and filtration recovery of drug substance. The filtration was done through 2" Sartobran P filter at 1.5 bar pressure. The bulk temperature range evaluated was $20^{\circ} \mathrm{C}-25^{\circ} \mathrm{C}$ and $35{ }^{\circ} \mathrm{C}-40$ ${ }^{\circ} \mathrm{C}$. Time required to filter predefined volume of drug product was evaluated to assess the impact of bulk temperature on throughput Table 2.

Table 2: Filtration Temperature

\begin{tabular}{|c|c|c|c|}
\hline \multirow{4}{*}{$\begin{array}{l}\text { Time required for } \\
\text { filtration }\end{array}$} & Amount filtered & Trial at $20 \circ \mathrm{C}-25 \circ \mathrm{C}$ & Tiral at $35^{\circ} \mathrm{C}-40{ }^{\circ} \mathrm{C}$ \\
\hline & $30 \mathrm{ml}$ & $9 \mathrm{sec}$ & $7 \mathrm{sec}$ \\
\hline & $35 \mathrm{ml}$ & $145 \mathrm{sec}$ & $65 \mathrm{sec}$ \\
\hline & $40 \mathrm{ml}$ & $173 \mathrm{sec}$ & $64 \mathrm{sec}$ \\
\hline
\end{tabular}

\section{Cycle Development:}

Freezing: Based on the glass transition temperature, the product was loaded onto precooled shelves, maintained at about $20^{\circ} \mathrm{C}$ and product being protein in nature, freezing was done in a staged manner to a product temperature of $-45^{\circ} \mathrm{C}$ as the drug product contains albumin. Freezing was initiated at $-5^{\circ} \mathrm{C}$ as an initial preparation stage for freezing at $-30^{\circ} \mathrm{C}$. Freezing was carried out at $-30^{\circ} \mathrm{C}$ for 2 hours so as to have controlled nucleation. Later the product was frozen at $-45^{\circ} \mathrm{C}$ for 4 hours above the freezing point temperature to ensure complete freezing of the product before initiation of primary drying. Primary Drying: Following the freezing step, the primary drying was performed in staged manner considering the low glass transition temperature of the solution as below:
Primary drying was initiated at $-45^{\circ} \mathrm{C}$ (kept for 45 minutes) and then at $-12^{\circ} \mathrm{C}$ (kept for 60 minutes) as an initial preparation stage $(0.12$ mbar). A pressure of about 0.12 mbar, which about $40 \%$ of the vapor pressure over ice at $12^{\circ} \mathrm{C}(0.3082$ mbar) was kept to maintain the pressure gradient for sublimation.

Secondary Drying: After completion of the primary drying and the shelf temperature was initially ramped to $20^{\circ} \mathrm{C}$ for 2 hours and then finally was dried at $35^{\circ} \mathrm{C}$ for 5 hours to achieve lowest possible water content and Degradation products.

The suitability of the lyophilization cycle was evaluated as shown in table 3 ,

Table 3: Lyophilisation Recipe

\begin{tabular}{|c|l|l|l|l|}
\hline S. No. & Processing Parameter & Time (h:m) & Temperature (oC) & Vacuum (mbar) \\
\hline 1. & Precooling/Start Value & $00: 00$ & 20 & Off \\
\hline 2. & Freezing & $00: 30$ & -5 & Off \\
\hline 3. & Freezing & $01: 30$ & -5 & Off \\
\hline 4. & Freezing & $00: 40$ & -30 & Off \\
\hline 5. & Freezing & $02: 00$ & -30 & Off \\
\hline 6. & Freezing & $00: 30$ & -45 & Off \\
\hline 7. & Freezing & $04: 00$ & -45 & Off \\
\hline 8. & Sublimation & $00: 30$ & -45 & Off \\
\hline 9. & Sublimation & $00: 30$ & -45 & 0.120 \\
\hline 10. & Sublimation & $01: 00$ & -12 & 0.120 \\
\hline 11. & Sublimation & $25: 00$ & -12 & 0.120 \\
\hline 12. & Sublimation & $00: 15$ & -12 & 0.120 \\
\hline 13. & Sublimation & $37: 00$ & -12 & 0.120 \\
\hline 14. & Sublimation & $00: 30$ & 20 & 0.018 \\
\hline 15. & Sublimation & $02: 00$ & 20 & 0.018 \\
\hline 16. & Sublimation & $01: 00$ & 35 & 0.018 \\
\hline 17. & Sublimation & $05: 00$ & 35 & 0.018 \\
\hline & & & Total time: $81: 55$ hrs & \\
\hline
\end{tabular}


Particle size, Size Distribution, Zeta Potential and Surface Morphology:

The size, size distribution, and zeta potential of the HSA nanoparticles were determined after sonication and after HPH with the dynamic light scattering (DLS) method using a Malvern Zetasizer NanoZS (Malvern Instruments, Worcestershire, UK). In addition, the shape and surface morphology of the HSA nanoparticles were characterized after sonication and after HPH using a scanning electron microscope (SEM) (KYKY-EM3200, KYKY Technology, Shanghai, China). In addition, the particles' resolution was shown with transmission electron microscopy (TEM) (CM30 $300 \mathrm{kV}$, Berlin, Germany).

Drug-Loading Capacity and Encapsulation-Efficiency Assays:
To determine the concentration of free pacitaxal, one aliquot of the HSA-PXT-NPs was ultrafiltered on a glass membrane filter and $200 \mu \mathrm{l}$ of the filtrate was mixed with $800 \mu \mathrm{l}$ acetonitrile, and vortexed for $3 \mathrm{~min}$. An aliquot of the same HSA-PXT-NPs $(200 \mu \mathrm{l})$ was mixed with $800 \mu \mathrm{l}$ acetonitrile and vortexed for $3 \mathrm{~min}$ without other process to determine the concentration of total pacitaxal. Pacitaxal concentration was then measured by high performance liquid chromatography (HPLC). A Hypersil ODS-2 C18 reverse phase column $(5-\mu \mathrm{m}$ particle size, $250 \mathrm{~mm} \times 4.6 \mathrm{~mm})$ (Youngling HPLC) was used in the analysis and the mobile phase used consisted of $70 \%(\mathrm{v} / \mathrm{v})$ acetonitrile and $30 \%$ deionized water as an isocratic system. Flow rate was 1.2 $\mathrm{ml} / \mathrm{min}$. Encapsulation, drug-loading capacity and encapsulation efficiency were calculated as follows:

$$
\begin{aligned}
& \text { Drug }_{\text {encapsulated }}=\text { Drug }_{\text {total }}-\text { Drug }_{\text {filtrate }} \\
& \text { Drug-loading capacity }(\%)=\frac{\text { Drug encapsulated }_{\text {Amount of HSA-NPs }}}{\text { Amou }} \times 100 \% \\
& \text { Encapsulation efficiency }(\%)=\frac{\text { Drug encapsulated }_{\text {Drug total }}}{\text { D }_{\text {a }}} \times 100 \%
\end{aligned}
$$

\section{RESULTS AND DISCUSSIONS}

\section{Description after Reconstitution Solution and} Reconstitution time

The lyophilized drug product is dissolved in $10 \mathrm{ml}$ water for injection for reconstitution. The water for injection should be flushed into the vial from the side of the glass wall. The vial is vigorously shaken to reconstitute the solution. The approx. time required is around 20 minutes.

\section{Particle Size}

The primary emulsion was further processed with high pressure homogenization and solvent evaporation to get the final bulk. Final bulk was again evaluated for Particle size distribution and Polydispersity index. The result was show in table 3 . The particle size of the reconstituted solution is checked using the laser diffraction technique (Fig.1).

Table 3: Particle size measurement

\begin{tabular}{|l|l|l|l|l|}
\hline Mixer and RPM & \multicolumn{4}{|c|}{ PSD (nm) of final bulk } \\
\hline & D10 & D50 & D75 & D90 \\
\hline Higher Shear Mixer at 2800 RPM & 155 & 247 & 322 & 414 \\
\hline High Shear homogeniser at 17000 RPM & 155 & 249 & 327 & 409 \\
\hline
\end{tabular}

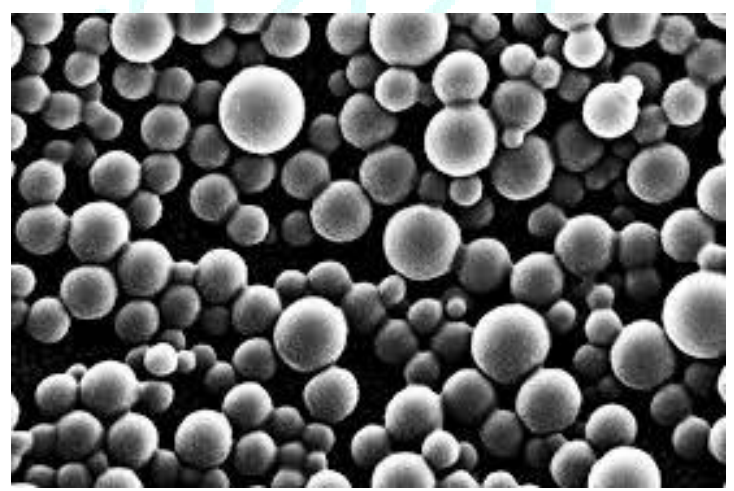

Figure1: Size distribution of nanoparticles preparation which shows that the particle diameters of both methods could be adjusted between 100 and $200 \mathrm{~nm}$

\section{Drug-Loading Capacity and Encapsulation-Efficiency Assays}

To determine the concentration of free pacitaxal, A Hypersil ODS-2 C18 reverse phase column $(5-\mu \mathrm{m}$ particle size, 250 $\mathrm{mm} \times 4.6 \mathrm{~mm}$ ) (Youngling HPLC ) was used in the analysis and the mobile phase used consisted of $70 \%(\mathrm{v} / \mathrm{v})$ acetonitrile and $30 \%$ deionized water as an isocratic system. Flow rate was $1.2 \mathrm{ml} / \mathrm{min}$. the Rt found to be $5.1 \mathrm{~min}$ fig 2 and fig 3, which are near to stander drug. Encapsulation, drug-loading capacity was found to be $98 \% \mathrm{w} / \mathrm{w}-99 \% \mathrm{w} / \mathrm{w}$.

By using HPLC method, the active drug content in the product is obtained. 


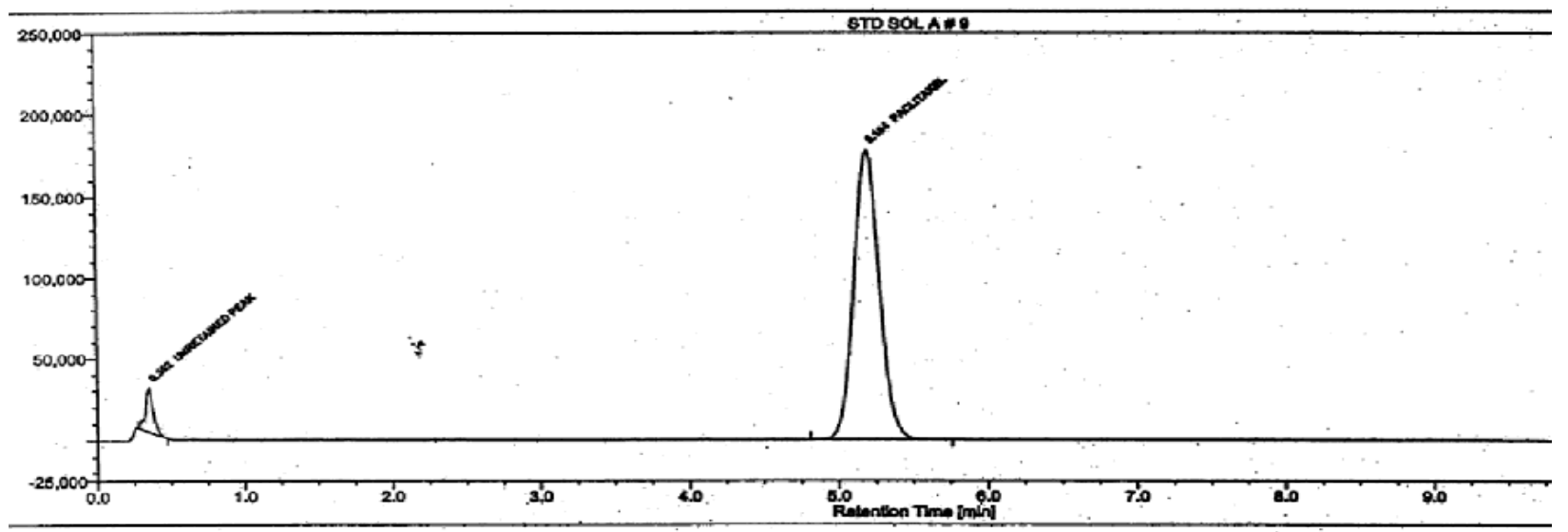

Figure 2: Chromatogram of Standard

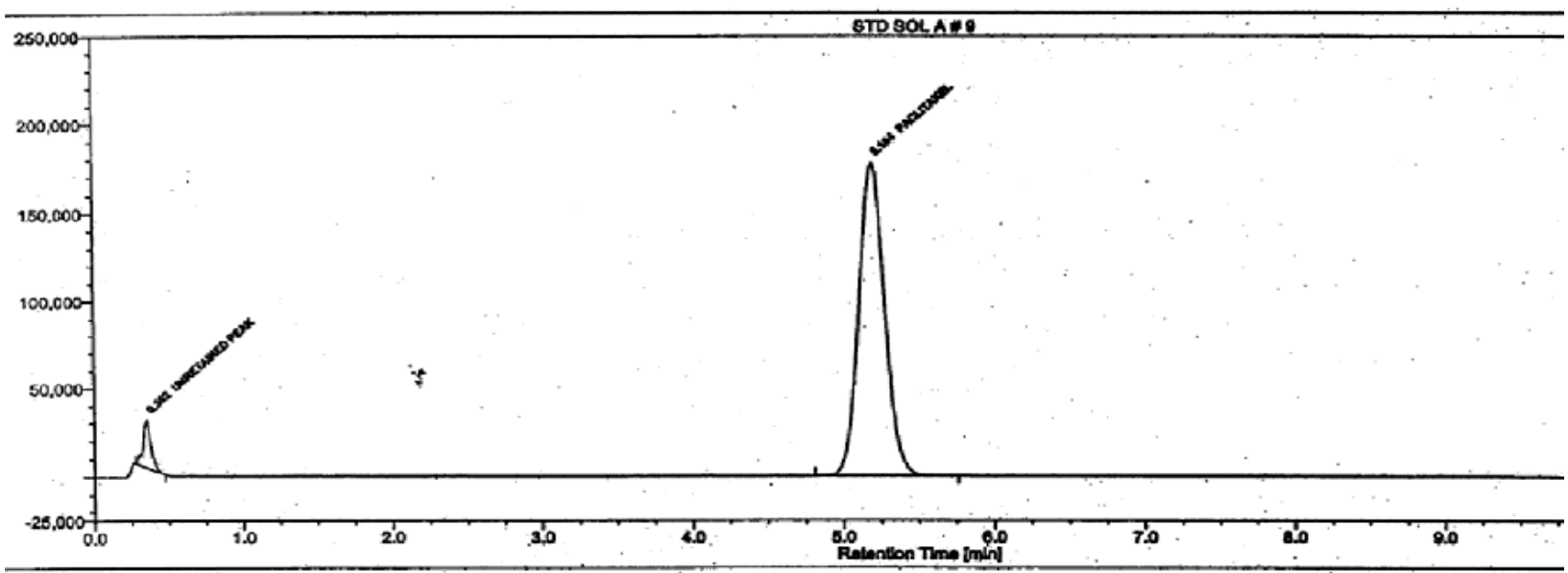

Figure 3: Chromatogram of sample solution

The description of nanoparticles of Paclitaxel before and after reconstitution and reconstitution time given in Table 4 . The average size and size distribution for each preparation was the results are given in table 4 . The suspensions of nanoparticles (as initially formulated in water for injection) remained homogeneous and stable for 3-5 days before showing significant aggregation. The nanoparticles also appear to suspend in an aqueous environment as individual particles with a spherical shape. The mean percent yield was found to be near $100 \%$ with a low of 98.9 (PTX) to high of 99.7 (blank). The drug loading efficiency and encapsulation efficiency was also near $100 \%$ similar to the percent yield.

Table 4: Test Results

\begin{tabular}{|l|l|l|}
\hline Test & Specification & Results \\
\hline Description & White to yellow lyophilized cake or powder & Complies \\
\hline Description after reconstitution & $\begin{array}{l}\text { Homogeneous milky suspension without visible } \\
\text { particulates }\end{array}$ & White milk suspension. \\
\hline Reconstitution time & NMT 25 minutes & 20.45 sec. \\
\hline Identification & $\begin{array}{l}\text { By HPLC The retention time of Paclitaxel peak obtained in } \\
\text { sample corresponds to the respective standards obtained } \\
\text { from standards }\end{array}$ & Meet the requirement \\
\hline pH & NLT 6.00 to NMT 8.00 & 7.16 \\
\hline Water content & NMT 3.00 \% w/w & $1.8 \%$ \\
\hline Particle size & NLT 100 nm - NMT 200 nm & Meet the requirement \\
\hline Assay of Paclitaxel (\%) & Between $90.0 \%$ to $110.0 \%$ of label claim of Paclitaxel & $98.9 \%$ w \\
\hline Free Paclitaxel (\%) & NMT $10 \%$ & $2.0 \%$ \\
\hline Sterility & Should comply as per USP <71> & Not applicable. \\
\hline
\end{tabular}




\section{CONCLUSION}

Paclitaxel is one of the most effective anticancer drugs ever developed. It is active against a broad range of cancers. However, the current Taxol formulations have issues related to the use of Cremophor EL and ethanol. Since nano-delivery systems could have the potential to be free of Cremophor EL and ethanol, enhance Paclitaxel solubility, improve Paclitaxel pharmacokinetic profiles in vivo, decrease its side effects, passively or actively target to tumor sites due to the EPR (Enhanced Permeability and Retention) effect and the use of targeting ligands, respectively, nanotechnology is a very active research area in both academic and industrial settings. The preliminary evaluation of this nano technology evolved that the drug product is stable and further can be evaluation for exhibit batches.

\section{ACKNOWLEDGEMENTS}

The authors thank to Surendra Kumar Jain, Director, Sagar Institute of Research \& Technology-Pharmacy Bhopal, M.P., and Dr. Nilesh Jain to provide the support throughout the research work.

\section{CONFLICT OF INTEREST}

The authors declare that they have no conflict of interests.

\section{REFERENCES}

1. Jordan MA, Wilson L. Microtubules as a target for anticancer drugs. Nat Rev Cancer. 2004; 4:253-265.

2. Gelderblom H, Verweij J, Nooter K, Sparreboom A. Cremophor EL: the drawbacks and advantages of vehicle selection for drug formulation. Eur J Cancer. 2001; 37:1590- 1598.

3. Sparreboom A, van Tellingen 0 , Nooijen WJ, Beijnen JH. Nonlinear pharmacokinetics of paclitaxel in mice results from the pharmaceutical vehicle Cremophor EL. Cancer Res. 1996; 56:2112-2115.

4. Gallo JM, Li S, Guo P, Reed K, Ma J. The effect of P-glycoprotein on paclitaxel brain and brain tumor distribution in mice. Cancer Res. 2003; 63:5114-5117.

5. Berg SL, Tolcher A, O'Shaughnessy JA, Denicoff AM, Noone M, et al. Effect of Rverapamil on the pharmacokinetics of paclitaxel in women with breast cancer. J Clin Oncol. 1995; 13:2039-2042.

6. Fracasso PM, Westervelt P, Fears CL, Rosen DM, Zuhowski EG, et al. Phase I study of paclitaxel in combination with a multidrug resistance modulator, PSC 833 (Valspodar), in refractory malignancies. J Clin Oncol. 2000; 18:1124-1134.

7. Hawkins MJ, Soon-Shiong P, Desai N. Protein nanoparticles as drug carriers in clinical medicine. Adv Drug Deliv Rev. 2008; 60:876-885.

8. Purcell M, Neault JF, Tajmir-Riahi HA. Interaction of Taxol with human serum albumin. Biochim Biophys Acta. 2000; 1478:6168.
9. Paal K, Muller J, Hegedus L. High affinity binding of paclitaxel to human serum albumin. Eur J Biochem. 2001; 268:2187-2191.

10. John TA, Vogel SM, Tiruppathi C, et al. Quantitative analysis of albumin uptake and transport in the rat microvessel endothelial monolayer. Am J Physiol Lung Cell Mol Physiol. 2003; 284:L187-L196.

11. Minshall RD, Sessa WC, Stan RV, et al. Caveolin regulation of endothelial function. Am J Physiol Lung Cell Mol Physiol. 2003; 285: L1179-L1183.

12. Vogel SM, Minshall RD, Pilipovic M, Tiruppathi C, Malik AB. Albumin uptake and transcytosis in endothelial cells in vivo induced by albumin-binding protein. Am J Physiol Lung Cell Mol Physiol. 2001; 281:L1512-L1522.

13. Tiruppathi C, Song W, Bergenfeldt M, et al. Gp60 activation mediates albumin transcytosis in endothelial cells by tyrosine kinase-dependent pathway. J Biol Chem. 1997; 272:2596825975.

14. Vorum H. Reversible ligand binding to human serum albumin: Theoretical and clinical aspects. Dan Med Bull. 1999; 46:379399.

15. Abraxane $®$ : Prescribing information. Schaumburg, IL, Abraxis Oncol-ogy, a Division of American Pharmaceutical Partners, Inc; 2005

16. Desai N, Trieu V, Yao Z. et al. Increased antitumor activity, intratumor paclitaxel concentrations, and endothelial cell transport of Cremophor-free, albumin-bound paclitaxel, ABI007, compared with Cremophor-based paclitaxel. Clin Cancer Res. 2006; 12:1317-1324.

17. Desai N, Yao Z, Trieu V, et al. Evidence of a novel transporter mecha-nism for a Cremophorfree, protein-engineered paclitaxel (ABI-007) and enhanced in vivo antitumor activity in an MX-1 human breast tumor xenograft model. 25th Annual San Antonio Breast Conference Symposium, San Antonio, TX; 2002 December 11-14.

18. Ibrahim NK, Desai N, Legha S, et al. Phase I and pharmacokinetic study of ABI-007, a Cremophor-free, protein-stabilized, nanoparticle formulation of paclitaxel. Clin Cancer Res. 2002; 8:1038-1044.

19. Ibrahim NK, Samuels B, Page R, et al. Multicenter phase II trial of ABI-007, an albumin- bound paclitaxel, in women with metastatic breast cancer. J Clin Oncol. 2005; 23(25):60196026.International Journal of Nanomedicine 2009:4 105

20. Gradishar WJ, Tjulandin S, Davidson N, Shaw H, Desai N, Bhar P, et al. Phase III trial of nanoparticle albumin-bound paclitaxel compared with polyethylated castor oil-based paclitaxel in women with breast cancer. J Clin Oncol. 2005; 23(31):77947803.

21. Nyman DW, Campbell KJ, Kristen Long EH, et al. Phase I and phar-macokinetics trial of ABI-007, a novel nanoparticle formulation of paclitaxel in patients with advanced nonhematologic malignancies. J Clin Oncol, 2005; 23(31):77857793. 